Como citar: TORRES, Glaucia Cardoso Teixeira. MUNIZ, Tânia Lobo Muniz. A construção da consciência ambiental e a importância das Organizações Internacionais no enfrentamento das questões ambientais globais. Revista do Direito Público. Londrina, v.11, n.1, p.183-204, jan/abr.2016. DOI: $10.5433 / 1980-511 \mathrm{X}$. 2016v11n1p183. ISSN: 1980$511 X$.

* Mestranda em Direito Negocial na Universidade Estadual de Londrina. Bolsista CAPES. Professora de Direito Internacional Privado na Faculdade Dom Bosco - PR. E-mail: glauciatorres2@gmail.com

** Professora associada da Universidade Estadual de Londrina. Docente dos cursos de graduação, especialização e mestrado em Direito. Doutora em Direito pela PUC-SP. E-mail: lobomuniz@gmail.com

\section{A construção da consciência ambiental e a importância das Organizações Internacionais no enfrentamento das questões ambientais globais}

\section{THE CONSTRUCTION OF ENVIRONMENTAL} AWARENESS AND THE IMPORTANCE OF INTERNATIONAL ORGANIZATIONS TO FACE GLOBAL ENVIRONMENTAL ISSUES

\author{
* Glaucia Cardoso Teixeira Torres \\ ** Tânia Lobo Muniz
}

Resumo: O trabalho, utilizando a revisão bibliográfica da literatura especializada, bem como a análise documental indireta de relatórios institucionais produzidos pelas organizações internacionais, aborda a construção e o fortalecimento da consciência ambiental no âmbito internacional. Inicialmente realiza uma contextualização do sistema de produção contemporâneo e do fenômeno da globalização e suas influências sobre o meio ambiente. Discute as principais conferências organizadas pelas Organizações das Nações Unidas e quais foram suas principais contribuições para a elevação da discussão da questão ambiental na agenda global. Reflete, ao final, sobre a importância das Organizações Internacionais como articuladoras dos Estados em torno da preservação ambiental no contexto globalizado contemporâneo.

Palavras-chave: consciência ambiental; Conferências; Organizações Internacionais.

Abstract: The work, using the literature review of the literature and the indirect documentary analysis of institutional reports produced by international organizations, focuses on the development and strengthening of environmental awareness at the international level . Initially performs a context of contemporary production system and the phenomenon of globalization and its influence on the environment. Discusses the major conferences organized by the United Nations Organizations and what were their main contributions to the increase of the environmental issue discussion on the global agenda . Reflects at the end, about the importance of International Organizations as articulators of states around the environmental preservation in the contemporary global context .

Keywords: environmental awareness; conferences; International organizations. 


\section{INTRODUÇÃO}

O século XX pode ser apontado como o marco histórico em que a consciência ambiental começou a ser desenhada de modo efetivo. Naquele momento constatava-se que os efeitos deletérios ambientais oriundos do crescimento econômico não seriam naturalmente reciclados pela natureza como se acreditara até então.

O sistema fragmentado e desterritorializado, característicos da globalização, potencializaram a produção. Todavia, este aumento impactou sobre o meio ambiente, suscitando a necessidade do fortalecimento da conscientização ambiental e da busca por um modelo de desenvolvimento que compatibilizasse crescimento econômico com questões sociais e ambientais. Nesse contexto foram realizadas importantes conferências no âmbito da Organização das Nações Unidas (ONU).

A interconectividade propiciada pela globalização reforça a importância do papel das Organizações Internacionais (OI), na articulação dos Estados, e de outros atores globais, no estabelecimento de políticas ambientais internacionais e no enaltecimento ao princípio da cooperação entre os Estados, nos assuntos relativos ao meio ambiente.

Tratar do debate das questões ambientais no contexto internacional mostra-se muito importante uma vez que é a partir do estabelecimento destas discussões que se fortalece a consciência ambiental, tanto no âmbito nacional quanto internacionalmente. Ademais, para responder satisfatoriamente às questões ambientais, dado seu caráter transfronteiriço, a cooperação dos Estados possibilitada por intermédio das Nações Unidas apresenta-se como solução imprescindível.

A fim de melhor explicitar tais questões, o trabalho se divide em três partes. Primeiramente apresenta as mudanças relativas ao sistema produtivo em um contexto globalizado. Em um momento posterior analisa as principais conferências realizadas no âmbito da ONU e seus documentos basilares.

No terceiro tópico aborda a importância das Organizações Internacionais como articuladoras dos Estados em torno das questões ambientais.

Ao final, a conclusão a que se pretende chegar consiste na imprescindibilidade da união dos Estados através da mediação das Organizações Internacionais como mecanismo de enfrentamento das questões ambientais em um contexto globalizado. 
Na investigação das temáticas, resgata-se aquilo que é pertinente para a pesquisa, por meio de uma compilação de conceitos teóricos e da análise de documentos que, associados conduzem a uma análise da consciência ambiental no âmbito internacional e da necessidade de solidificação do princípio da cooperação entre os Estados, através de uma abordagem cujo viés passa pelas perspectivas econômicas, políticas e ambiental.

\section{O MODO DE PRODUÇÃO CONTEMPORÂNEO E A INTERCONECTIVIDADE GLOBAL}

Embora a Revolução Industrial tenha sido o marco de expansão da produção industrial, foi no século XX, em um contexto globalizado, que o conceito da consciência ambiental ganhou destaque no cenário internacional.

A emergência do Estado liberal e da Revolução Industrial levou à expansão da produção e ao crescimento econômico. A substituição da manufatura pela máquina deu início à produção em massa, fator que potencializou enormemente a industrialização. Neste momento, a razão técnica desenvolveu a eficiência da apropriação e domesticação dos recursos naturais. Contudo, a crença alimentada com o triunfo do liberalismo clássico do final do século XVIII de que a iniciativa privada, ao perseguir seus próprios interesses, naturalmente promoveria o interesse dos demais mostrou suas falhas. A expansão da produção e o desenvolvimento econômico decorrentes não trouxe somente efeitos positivos como pregavam seus idealizadores, mas também efeitos deletérios decorrentes da produção em massa.

A máxima de que cada um deve ocupar-se do próprio negócio permitiu que uma série de resultantes da produção não participassem do cálculo privado, o que conduziu a uma sequência de "deseconomias", ou seja, produtos não contabilizados na renda do empreendedor, trazendo efeitos negativos à sociedade, externalidades negativas. Ao contrário do que previam os liberais clássicos, a perseguição de interesses individuais não conduz apenas ao aumento dos benefícios públicos, externalidades positivas; mas também, tragicamente à destruição da base comum da manutenção da vida. (DERANI, 2001,p. 112)

O desenvolvimento econômico ocorreu simultaneamente à crescente interdependência dos países que teve seu início no final do século XVIII. Alguns 
marcos históricos como a segunda guerra mundial fomentaram o sistema internacional bem como o crescimento de determinados países, interligando a economia mundial. (WILLIAMSON, 1998, p.14)

Esta interconexão entre os países aliada aos avanços tecnológicos desencadearam o fenômeno da globalização. Tal fenômeno modificou as faces do sistema produtivo que passou a caracterizar-se pela fragmentação e especialização da produção. O sistema anterior de inspiração fordista, calcado na ideia de linha de montagem era composto de gigantes plantas industriais nas quais concentrava sua produção acarretando a necessidade de grande concentração de mão-de-obra, enorme mobilidade de recursos e baixa mobilidade da produção. (MARQUES NETO, 2002, p.107)

As inovações tecnológicas ocorridas no século XX concederam novo impulso às grandes indústrias. Seu extraordinário poder ultrapassou não apenas as fronteiras nacionais dos países onde se encontravam sediadas, mas também o próprio âmbito econômico, tendo influência inclusive no campo político. Originavam-se, então, as empresas multinacionais. (BULGARELLI, 1987, p.19).

O novo sistema produtivo composto de uma rede na qual vários micro processos independentes vão se somando e integrando permite tanto a agregação de componentes elaborados e advindos de vários países como a mobilização do aparato produtivo de um país realocando-o em outro, deste modo o sistema produtivo atual prescinde de uma única nação. Há uma total desconexão entre a estrutura produtiva e o nexo territorial nacional. Além disso, o sistema de produção flexível utiliza-se da terceirização e da parceria como novas estratégias de produção. (MARQUES NETO, 2002, p.107).

A empresa global de hoje é uma rede constituída por elementos complementares, espalhados pelo planeta, que se articulam entre si segundo uma racionalidade econômica pura. A interconectividade propiciada pela globalização permite que uma empresa espanhola requeira um crédito na Suíça, instale seus centros de pesquisa na Alemanha, compre suas máquinas na Coréia do Sul, monte suas fábricas na China, elabore suas campanhas de marketing e publicidade na Itália e venda aos Estados Unidos. (RAMONET, 2007, p. 9596)

Este contexto de interconectividade global potencializa os danos ambientais ocasionados pela presença das transnacionais. O modelo de produção contemporâneo possibilitou o expressivo crescimento econômico 
das empresas transnacionais e consequentemente maiores danos ocorreram ao meio ambiente.

Cristiane Derani faz uma relação entre ecologia e economia em seu livro Direito Ambiental Econômico:

O antagonismo gerado entre ecologia e economia que especificamente hoje é possível de ser identificado pode ser formulado do seguinte modo: ecologia está assentada numa descrição de tempo e espaço e os processos de transformação da matéria-prima são exercidos sobre um conjunto finito. A economia, ou melhor, o modo de produção moderno, não leva em consideração o tempo e o espaço, tomando os recursos naturais como infinitos e inesgotáveis, justificando a necessidade de um contínuo crescimento, que se revela por uma geração constante de valor, início e fim de toda produção" (2001,p. 122)

Outro aspecto que impacta no meio ambiente, advindo do sistema de produção contemporâneo, consiste na facilidade de realocação das unidades das transnacionais ao redor do globo. A grande mobilidade possibilitada pelo novo aparato produtivo corroborou para a inexistência de vínculo entre a empresa e o local onde desenvolverá suas atividades, vez que há a possibilidade de operar em diversas localidades. Diante de maiores possibilidades lucrativas e menor burocratização, as transnacionais mudam a localidade de suas unidades com extrema facilidade. Partem levando consigo seu capital e deixando para trás os efeitos deletérios ambientais causados por suas ações.

Nesse sentido Zygmunt Bauman (1999, p.15) dispõe:

[...] a localização onde se desenrola o sistema produtivo da empresa pouco ou nada influencia na decisão do investidor de em qual companhia investirá. É a possibilidade de lucro que determina a escolha. A empresa, por sua vez, move suas unidades para onde percebe ou preveja uma chance de dividendos mais elevados. E quando isso ocorre deixa a todos os demais, presos que estão à localidade, a tarefa de "lamber as feridas, consertar o dano e se livrar do lixo". A companhia é livre para se mudar, mas os efeitos deletérios desta mudança estão destinados a permanecer.

O fenômeno da globalização elevou a questão da conservação da natureza a uma perspectiva mundial, tanto pela destruição ambiental que desconhece 
fronteiras quanto pela sua vinculação à dinâmica do mercado internacional. (DERANI, 2001, p. 126).

A questão que se impõe consiste em que os mecanismos de regulamentação de condutas transnacionalizadas não acompanharam as inúmeras manobras possíveis às transnacionais causadas pela interconectividade característica da globalização. $\mathrm{O}$ conceito de jurisdição foi forjado em torno de marcos territoriais delimitados, havendo, portanto, um descompasso entre a possibilidade de tutela na esfera dos Estados e as manobras realizadas pelas empresas globais em um contexto globalizado.

Além disso, dentro deste panorama de interconexão entre os diversos países, a questão da conservação compõe uma perspectiva global, não apenas pelos efeitos da destruição ambiental que não se limitam às fronteiras territoriais, mas principalmente por sua vinculação à dinâmica do mercado internacional. A destruição do meio ambiente encontra-se inserida em um processo global de expansão da produção. E a dinâmica entre causa e efeitos desta destruição não estão ligadas obrigatoriamente ao mesmo território. (DERANI, 2001, p. 126)

A expansão da produção po.tencializada pelo fenômeno da globalização tornou evidente os efeitos deletérios causados ao meio ambiente, não sendo possível, por conseguinte, tratar das questões econômicas e ambientais de maneira estanque. A economia e o meio ambiente mostraram-se ao longo do tempo intrinsecamente ligados, vez que a ação da primeira não ocorria sem causar efeitos, na maior parte das vezes negativos, no segundo. Ademais as duas esferas constituem ramos importantes ao bem-estar humano. Nesse sentido a partir de meados do século XX suscitou-se a necessidade de forjarse políticas que buscassem a tutela do meio ambiente aliada ao desenvolvimento econômico.

A falta de um órgão legislador com competência supranacional para normatizar os fundamentos do crescimento econômico vigente, regulando o uso ilimitado de recursos limitados e buscando tutelar o meio ambiente, incitou as Organizações Internacionais a formularem políticas ambientais internacionais que, posteriormente, passariam a influenciar os ordenamentos jurídicos internos dos países. 


\section{O FORTALECIMENTO DA CONSCIÊNCIAAMBIENTAL E OS PRINCIPAIS DOCUMENTOS NO ÂMBITO DA ONU EM MATÉRIAAMBIENTAL}

Embora o homem seja um ser que nasce, vive e morre no meio ambiente, dele necessitando para uma vida saudável, não é da sua natureza intrínseca cuidar deste ambiente. Salvo raras exceções, as pessoas mantiveram durante muitos anos uma relação de domínio com a natureza, sempre em busca de prover seu sustento e de sua família, sem preocupar-se se o ambiente natural manteria seu status quo.

Nesse sentido, Granziera (apud QUAGLIA, 2012, p. 67) expõe:

[...] a proteção do ambiente não faz parte da cultura nem do instinto humano. Ao contrário, conquistar a natureza sempre foi o desafio do homem, espécie que possui uma incrível adaptabilidade aos diversos locais do planeta e uma grande capacidade de utilizar os recursos naturais em seu benefício. Essas características fizeram com que ao longo do tempo, a natureza fosse dominada pelo homem, que no entanto, não se preocupou com os danos que esse desenvolvimento causava.

Guido Soares (2001, p. 35) destaca que o início século XX herdou dos séculos anteriores a ideia potencializada durante a Revolução Industrial de que o desenvolvimento material das sociedades consistia no valor supremo a ser almejado. $\mathrm{O}$ fato de que as atividades industriais produzem um subproduto altamente maléfico para natureza e, consequentemente, para o próprio homem foi por muito tempo ignorado. Inexistia uma preocupação ambiental por acreditar-se que a natureza absorveria os produtos nocivos gerados pela produção industrial. O que ocorreu, contudo, foi um momento em que claros indícios apontavam que a natureza não reciclaria os materiais tóxicos como esperado.

O desenvolvimento da tecnologia foi um importante fator no fortalecimento da conscientização ambiental. Os avanços tecnológicos permitiram o monitoramento da degradação ambiental e o desenvolvimento de modernos computadores que propiciaram o confrontamento entre o crescimento econômico e as consequências para o meio ambiente. (DUARTE, 2004, p.7). 
O acelerado crescimento econômico ocorrido após a segunda guerra mundial aliado aos avanços tecnológicos que permitiam uma confrontação dos indícios de que o meio ambiente vinha sofrendo os efeitos do modo de produção vigente suscitou questionamentos. Em 1972, o Clube de Roma publicou um Relatório intitulado "Os Limites do Crescimento" no qual trazia o alerta de que caso a exploração dos recursos e a industrialização continuassem no ritmo e da maneira como vinham ocorrendo, as fontes naturais certamente se esgotariam. (SOARES, 2001, p. 50).

No estudo, fazendo uma projeção para cem anos, sem levar em conta o progresso tecnológico e a possibilidade de descoberta de novos materiais, apontou-se que, para atingir a estabilidade econômica e respeitar a finitude dos recursos naturais, era necessário congelar o crescimento da população global e do capital industrial (WADA, 2015). O estudo teve grande impacto, sendo traduzido em 30 idiomas e vendido em vários países.

As questões ambientais entravam nas pautas das agendas internacionais. No mesmo ano em que foi elaborado o relatório "Os limites do crescimento", a ONU realizou a Conferência das Nações Unidas sobre o Meio Ambiente Humano, também conhecida por Conferência de Estocolmo.

Muitos foram os frutos desta conferência, dela emanando a Declaração de Estocolmo, na qual, pela primeira vez, o direito ao meio ambiente foi considerado direito fundamental. O direito ambiental nascia para responder a um conflito interno da sociedade, interpondo-se no desenvolvimento de seus atos. A partir daí as normas ambientais deveriam refletir a constatação social paradoxal resumida no seguinte dilema: a sociedade deveria começar a agir dentro de seus pressupostos industriais que embora visassem o prazer e o bem-estar podiam acarretar desconforto, doença e miséria? (DERANI, 2001, p. 80).

No contexto em que ocorreu a conferência de Estocolmo constatavase que a sociedade e seu modo de produção não mais poderiam ser concebidos de maneira autônoma em relação à natureza. Ulrich Beck (2010, p. 99) dispõe que problemas ambientais não podem ser dissociados do contexto social onde ocorrem, vez que é a partir do universo civilizatório, industrializado que os danos ambientais ocorrem.

Nesse sentido, a conferência buscou desenhar as primeiras linhas de uma relação de equilíbrio entre desenvolvimento econômico e preservação ambiental. 
A Conferência estabeleceu algumas ações para auxiliar a preservação ambiental e o desenvolvimento dos países. A Declaração adotada pela Conferência de Estocolmo é a verdadeira carta de proteção ambiental em nível internacional. Trata-se da Declaração de Estocolmo ou Declaração das Nações Unidas sobre o Meio Ambiente Humano, composta por 26 princípios, a qual, conforme entendimento da doutrina, representa instrumento de inequívoca importância para o direito internacional do meio ambiente, semelhante à da Declaração Universal dos Diretos Humanos, de 1945, no que se refere à proteção dos direitos humanos. (OLIVEIRA e ALVERNE, 2015, p. 121).

$\mathrm{Na}$ Conferência de Estocolmo também foi ressaltada a necessidade de repensar os conceitos tradicionais dos propósitos do crescimento, embora tenha sido expresso no artigo 37 da referida Declaração que o modelo de crescimento zero proposto pelo Clube de Roma não era viável para a sociedade. Outro avanço significativo constituiu na instituição do Programa das Nações Unidas para o Meio Ambiente (PNUMA), Programa de meio ambiente que procurou desenvolver programas de monitoramento dos níveis de poluição, desmatamento e desertificação do meio ambiente global. Desde sua criação, o PNUMA tem buscado equilibrar interesses nacionais e globais, incitando convergências em relação a problemas ambientais comuns. $\mathrm{O}$ PNUMA consiste na única instituição das Nações Unidas que cuida exclusivamente de temas ambientais. Atua como catalisador de ações que estimulam a conscientização ambiental, buscando parceria com outras organizações, e programas do sistema das Nações Unidas, com o objetivo de desenvolver atividades em benefício do meio ambiente. (PNUMA)

A Conferência também reconheceu expressamente a disparidade existente entre os países que influenciam na aplicação dos padrões internacionalmente acordados para o meio ambiente e destacou a necessidade de os países cooperarem entre si, para que os acordos firmados a nível internacional em relação ao meio ambiente fossem cumpridos.

Embora o princípio da cooperação tenha aparecido já no artigo 1 da Carta das Nações Unidas 1945, em matéria ambiental a importância de tal princípio foi ressaltada na Conferência de Estocolmo. Pela primeira vez percebia-se que o caráter transfronteiriço das questões ambientais suscitava a necessidade da união dos países na busca de soluções para os problemas ambientais. Essa articulação entre os países se deu a partir das ações das 
Organizações Internacionais, de modo especial da ONU que liderou outras importantes conferências.

A partir de 1972, a discussão acerca dos temas ambientais não mais saiu das agendas internacionais. A preocupação com a questão ambiental no âmbito internacional influenciou a multiplicação de acordos bilaterais e multilaterais.

Em 1985, a Convenção de Viena dispôs a necessidade de harmonização das políticas no que diz respeito a evitar, limitar e controlar as atividades humanas causadoras de danos à camada de ozônio. Dois anos depois o Protocolo de Montreal estabeleceu em retorno gradual da produção e do consumo de substâncias controladas.

A discussão seguiu no sentido de buscar um modelo de desenvolvimento que compatibilizasse a preocupação com as questões ambientais. Os economistas Ezra Mishan e Arthur Pigou, por exemplo, dispuseram que o crescimento econômico, especialmente quando refletido pelo Produto Interno Bruto (PIB), não era capaz de contabilizar determinados custos oriundos do consumo e produção, as chamadas "externalidades negativas. Além disto, o preservacionismo radical defendido por muitos ambientalistas, nas décadas de 1970 e 1980, não era solução, porque impunha restrições ao bem-estar humano. O que estava em jogo era a inexistência de uma abordagem que pudesse conciliar tanto a garantia de bem-estar aos indivíduos, quanto a conservação e utilização racional dos recursos naturais. (PLATIAU; VARELLA; SCHLEICHER, 2004, p.2)

Em 1987 a consciência ambiental havia evoluído, percebia-se que os recursos naturais não eram inesgotáveis e que a natureza não reciclaria os efeitos deletérios do crescimento econômico naturalmente, sendo, portanto, fundamental pensar-se em desenvolvimento a partir da noção de sustentabilidade. Nesse contexto, foi elaborado pela Comissão Mundial sobre o Meio Ambiente e Desenvolvimento, presidida pela primeira-ministra norueguesa Gro Harlem Brundtland, um relatório denominado Nosso Futuro Comum, também conhecido por Relatório Brundtland em que era concebido o conceito de desenvolvimento sustentável, como "o desenvolvimento que satisfaz as necessidades presentes, sem compreender a capacidade das gerações futuras de suprir suas próprias necessidades" (FRACCHIA, apud QUAGLIA, 2012, p. 69) 
Dentre as medidas elaboradas por tal relatório, a serem incorporadas pelos países a fim de promover o desenvolvimento sustentável, encontram-se a limitação do crescimento populacional, garantia de recursos básicos (água, alimento e energia) a longo prazo, preservação dos ecossistemas, diminuição do consumo de energia e o desenvolvimento de tecnologias que se utilizem de fontes energéticas renováveis, aumento da produção industrial em países não industrializados com base em tecnologias ecologicamente adaptadas, controle da urbanização desordenada, atendimento das necessidades básicas (saúde, moradia e educação). No âmbito internacional as metas propostas foram adoção de estratégias de desenvolvimento sustentável para órgãos e instituições internacionais de financiamento, proteção dos ecossistemas supranacionais (oceanos, Antártica) pela comunidade internacional, banimento das guerras, implantação de um programa de desenvolvimento sustentável pela ONU.

A realização do desenvolvimento sustentável assenta-se assim sobre dois pilares, um relativo à composição de valores materiais e outro voltado à coordenação de valores de ordem moral e ética consubstanciada em uma interação dos valores sociais onde interagem os interesses particulares de lucro e os interesses de bem-estar coletivo. A expressão desenvolvimento sustentável contém em si a ideia de que a expansão da atividade econômica deve estar vinculada a uma sustentabilidade tanto econômica quanto ecológica. Os criadores de tal expressão partem da constatação de que os recursos naturais são esgotáveis, mas se apoiam no postulado de que o crescimento constante da economia é necessário à expansão do bem-estar ao redor do mundo. (DERANI, 2001, p.133)

Gilberto Rodrigues (2006, p.202) ressalta que na perspectiva dos países, de modo especial nos da América Latina o impacto da década das conferências se fez sentir de modo muito forte sobre as políticas públicas, influenciando no traçado de novas políticas públicas ou reorientando as existentes.

Nesse cenário, em 1992 foi realizada no Rio de Janeiro, a Conferência ECO 92 tendo como principal objetivo a conciliação do desenvolvimento socioeconômico com a conservação e proteção dos ecossistemas da terra. Participaram desta Conferência 103 chefes de Estado e 176 delegações. A Conferência do Rio também ficou conhecida por Cúpula da Terra, pois se tratava da maior conferência já realizada pelas Nações Unidas até aquele momento. (OLIVEIRA e MONT'ALVERNE, 2015, p. 123) Tal conferência 
consagrou o conceito de desenvolvimento sustentável, contribuiu para que uma maior conscientização de que os danos ao meio ambiente eram majoritariamente de responsabilidade dos países desenvolvidos, reconheceu a necessidade de os países em desenvolvimento e os menos desenvolvidos receberem apoio financeiro e tecnológico para alcançarem o desenvolvimento sustentável. A Conferência contribuiu para a noção da necessidade da solidificação de uma equidade intrageração, ou seja, que a preservação passasse a ser percebida não só como algo necessário às futuras gerações como para a própria geração que vive as transformações ambientais. Foi elaborada a Carta da Terra, documento cuja meta principal consistia em motivar a todos os povos por meio da interdependência global, a olharem a Terra como lar comum de todos e fomentar a concepção de que a responsabilidade pelo meio ambiente deveria ser compartilhada por todos os países e todas as pessoas. Como produto dessa Conferência foram assinados 05 documentos. São eles: Declaração do Rio sobre Meio Ambiente e Desenvolvimento; Agenda 21; Princípios para a Administração Sustentável das Florestas; Convenção da Biodiversidade; Convenção sobre Mudança do Clima.

O documento emanado da RIO-92 considerado de maior importância foi a Agenda 21. Tal documento propunha um programa de ação com o cunho de viabilizar o novo padrão de desenvolvimento conciliando métodos de proteção ambiental, justiça social e eficiência econômica. Tal documento é o referencial para que os países elaborem o seu próprio plano de preservação do meio ambiente.

A preocupação dos cientistas quanto a anomalias nos dados de temperatura observados, que indicavam uma tendência de aquecimento global, incitou durante a Conferência das Nações Unidas sobre Meio Ambiente e Desenvolvimento ocorrida no Rio de Janeiro em 1992, a criação da ConvençãoQuadro das Nações Unidas sobre Mudança do Clima (UNFCCC).

A Convenção-quadro das Nações Unidas estabeleceu que deveria ocorrer anualmente a Conferência das Partes (COPs). Em decorrência da primeira Conferência das Partes (COP 1), realizada em 1995, na Alemanha, assim como da segunda (COP 2), que ocorreu em 1996 na Suíça, restou convencionado a necessidade da elaboração de um Protocolo com obrigações legais e metas vinculantes para a diminuição da emissão de gases do efeito estufa. Assim, na terceira Conferência das Partes (COP 3), realizada em 
1997, elaborou-se o Protocolo de Kyoto, que consistiu em um dos marcos mais importantes desde a criação da Convenção-quadro das Nações Unidas sobre Mudanças do Clima no Combate à mudança climática (LIMIRO, 2008, p. 37)

O Protocolo estabeleceu metas e prazos para a redução da emissão de poluentes e teve dificuldades em sua ratificação. O entrave consistiu no alto custo da adequação das matrizes energéticas. Os EUA declararam que não ratificariam o protocolo, pois não iriam submeter o avanço da economia norteamericana aos sacrifícios necessários para implementação das medidas propostas. (QUAGLIA, 2012, p. 88)

Em 2002, na cidade de Joahnesburgo foi realizada a Cimeira Mundial sobre o Desenvolvimento Sustentável, em comemoração aos 10 anos da RIO92, apesar das expectativas a reunião não obteve o sucesso esperado, não alcançando resultados expressivos em termos ambientais.

Em 2009, em Copenhagen, aconteceu a COPs 15. Nesta oportunidade, tentou-se o consenso em torno do chamado Acordo de Copenhague (AC). Todavia este não foi aprovado pela totalidade dos 192 países membros da Convenção. Apesar de ser politicamente frágil, o AC significou avanço no sentido de reconhecer a promoção de reduções de emissões resultantes de desmatamento e degradação florestal (REDD) como medida fundamental para mitigar os efeitos das mudanças climáticas. Como o encontro tinha por objetivo o estabelecimento do tratado que substituiria o Protocolo de Kyoto, vigente de 2008 a 2012, havia enorme expectativa em relação ao evento. Todavia, questões como o impasse entre países desenvolvidos e em desenvolvimento para se estabelecer metas de redução de emissões, bem como a recusa do governo americano em participar das discussões e do esforço de combate à mudança do clima, comprometeram que as mudanças prometidas fossem concretizadas. (COPs)

Em junho de 2012 foi realizada, novamente no Rio de janeiro, a Conferência das Nações Unidas sobre o Desenvolvimento Sustentável (CNUDS), a Rio+20. Seu principal objetivo era discutir sobre a renovação do compromisso político com o desenvolvimento sustentável. De acordo com o Secretário Geral das Nações Unidas, Ban Ki-moon, a conferência equilibrou as visões dos 193 Estados-Membros das Nações Unidas e reconheceu a pobreza como o maior desafio para o bem-estar econômico, social e ambienta. Os Estados-Membros concordaram em lançar um processo para estabelecer 
objetivos universais de desenvolvimento sustentável, embora as definições dos temas específicos bem como as metas para atingir tais objetivos não tenham sido fixados nesta ocasião. (COELHO; GOLDEWMBERG, 2015, p.12)

Recentemente, em 02 de agosto de 2015, depois de dois anos de negociações, que envolveram representantes dos 193 Estados-Membros da ONU e diversas organizações da sociedade civil, foram definidos os 17 Objetivos de Desenvolvimento Sustentável (ODS). Os ODS basearam-se nos Objetivos de Desenvolvimento do Milênio elaborados na declaração do Milênio da ONU em setembro de 2000.

Os ODS são uma série de escopos de caráter social, econômico e ambiental a serem alcançados pelos países de todo o mundo. Segundo a ONU, os Objetivos de Desenvolvimento do Milênio (ODM) ajudaram mais de 700 milhões de pessoas a sair da pobreza. Intitulado "Transformando Nosso Mundo: a Agenda 2030 para o Desenvolvimento Sustentável”, o documento final que contém os 17 ODS tem como principal ambição a erradicação da pobreza. Almeja ainda superar barreiras como a desigualdade social, o consumo e a produção insustentáveis, a infraestrutura inadequada e a falta de empregos decentes, sublinhando ainda a necessidade de uma cooperação internacional em muitas frentes para que os objetivos sejam alcançados.

Cada ODS é subdividido em diversas metas, 169 no total. Metas relacionadas ao tema "acesso à informação" estão citadas no ODS 16, enquanto que observações referentes ao direito à liberdade de expressão, transparência e responsabilização (accountability) permeiam todo o documento.

O acordo sobre os 17 ODS, oficialmente adotado em setembro de 2015, durante a realização da Cúpula do Desenvolvimento Sustentável, na sede da ONU, em Nova York, busca através do trabalho conjunto de governos e cidadãos de todo o mundo, criar um novo modelo global para erradicar a pobreza, promover a prosperidade e o bem-estar de todos, proteger o ambiente e combater as alterações climáticas. (ODS)

Também no ano de 2015 foi realizada a $21^{\mathrm{a}}$ COPs em Paris. Como aspecto positivo de tal evento pode-se ressaltar o estabelecimento de objetivos de limitação do aumento da temperatura em relação a níveis pré-industriais. Foram definidos processos de revisão para os compromissos de todos os 
países, objetivando a avaliação da adequação das metas de redução de emissões a uma trajetória compatível para limitar o aquecimento global. Contudo, há aspectos frágeis na referida conferência como por exemplo, a falta de uma data definida para a consecução de tais objetivos. (RITTI, 2015)

A falta de uma data limite para que os países implementem os objetivos relacionados à limitação do aumento da temperatura global consiste em um entrave ao êxito da $21^{\text {a }}$ COPs, vez que as ações dos Estados nesse sentido correm o risco de serem indefinidamente postergadas.

Percebe-se que nas questões ambientais globais não são a soberania e o interesse nacional que estão em discussão. A proteção dos direitos humanos e a conservação do meio ambiente tornaram-se uma questão de interesse internacional. (TRINDADE, 1993, p. 47)

Neste contexto, em matéria ambiental não é possível que os Estados intencionem solucionar as questões de maneira isolada. É imprescindível a articulação dos países a fim de que respostas eficientes de caráter global sejam elaboradas para a preservação do meio ambiente. Nesse contexto, as Organizações Internacionais apresentam-se como importantes instituições desse processo.

\section{O IMPORTANTE PAPEL DAS ORGANIZAÇÕES INTERNACIONAIS NAARTICULAÇÃO DOS ESTADOS EM TORNO DAS QUESTÕES AMBIENTAIS}

A ação da ONU na organização das conferências ambientais resultou na solidificação da consciência ambiental no âmbito internacional, na internalização da preocupação com o meio ambiente nos diversos ordenamentos jurídicos e na formulação de princípios do direito ambiental. Contudo, o fenômeno da globalização, altamente fortalecido neste início de século, evidencia a necessidade da cooperação entre os Estados no enfrentamento das questões ambientais.

A tensão existente entre economia e meio ambiente e os debates levantados nas Conferências internacionais relacionadas às questões ambientais levaram o direito a formular princípios ambientais com o escopo de "reorganizar o dilema exposto na contradição entre economia e ecologia. “ Tais princípios expressam a posição do direito em relação aos problemas ambientais, que diante dos alertas e discussões suscitados nas Conferências 
globais, desempenham seu papel de implementador de paradigmas que visem uma posição objetiva em prol da efetivação de medidas eficazes no controle da devastação ambiental. (DERANI, 2001, p. 154).

Cristiane Derani (2001, p.160-171) aponta três princípios ambientais fundamentais: o da precaução, do poluidor-pagador e da cooperação. Segundo a autora, o princípio da precaução representa a essência do direito ambiental uma vez que traduz a necessidade de uma atuação racional para com os recursos naturais. Além de tentativas de afastar riscos, este princípio visa garantir uma suficiente margem de segurança dos limites do risco de perigo, manifestando-se muito antes dos efeitos deletérios da ação econômica no meio ambiente tornarem-se evidentes. O princípio do poluidor-pagador objetiva a "internalização dos custos relativos externos da deterioração ambiental" O agente que ao desempenhar sua atividade econômica vier a causar algum dano ambiental, deverá, através desse princípio, arcar com os custos da diminuição ou afastamento do dano. A partir desse princípio políticas públicas foram desenvolvidas no sentido de além caber ao poluidor-pagador reparar o dano, estimular que este indivíduo econômico adote medidas que diminuam de fato a atividade danosa. O terceiro princípio abordado pela autora, princípio da cooperação, não consiste em exclusividade do direito ambiental. É, antes uma proposta de ação conjunta do Estado e da sociedade, na escolha de prioridades que orientem políticas relacionadas ao objetivo de bem-comum. Tal princípio encontra-se na base dos instrumentos normativos cujo objetivo consiste em equilibrar liberdade individual e necessidade social.

Embora o princípio da cooperação apareça desde a constituição da ONU, na Carta das Nações Unidas, foi na Convenção de Estocolmo, em 1972, que se destacou o dever de cooperação e reconhecimento da interdependência entre os Estados. Nesse sentido, a Declaração de Estocolmo sobre Meio Ambiente Humano elencou dois claros dispositivos. No primeiro (artigo 23) expressou-se o reconhecimento da disparidade existente entre os Estados, no que se refere à capacidade de aplicarem os padrões internacionalmente acordados para proteção do meio ambiente. No segundo (princípio 24) introduziu-se o dever de cooperação internacional para atingir tais objetivos. (SOARES, 2003, p.615).

A constatação de que as questões ambientais não poderiam ser enfrentadas de modo isolado ocorreu gradativamente. Nos primórdios da 
regulamentação ambiental internacional, voltou-se a atenção à proteção ambiental em zonas sob competência dos Estados, intraterritoriais. Posteriormente passou-se a considerar o caráter transfronteiriço dos problemas ambientais, enfatizando as relações entre países vizinhos. Todavia, não tardou para que se percebesse a necessidade de considerar as questões ambientais em escala global. (TRINDADE, 1993, p. 46).

O caráter global das questões ambientais reflete-se em vários temas ambientais. Como exemplos, podem-se citar a necessidade da conservação da diversidade biológica e a poluição atmosférica. Tais problemas, tidos inicialmente como essencialmente locais, mostraram-se ilimitados espacialmente. A ameaça de dano a muitas nações oriundas das alterações climáticas, por exemplo, é um problema grave cuja causa dificilmente poderia ser atribuída a um único Estado. A questão requer um enfoque com base em estratégias de prevenção e adaptação considerados a partir da cooperação internacional. Nesse sentido, a Assembleia Geral das Nações Unidas, na resolução 43/53, de 6 de dezembro de 1988, reconheceu as alterações climáticas como interesse comum da humanidade, e determinou seu enfrentamento em um âmbito global. (TRINDADE, 1993, p. 44).

Os fenômenos relacionados ao meio ambiente desconhecem as fronteiras artificiais instituídas entre os Estados. Como ressaltou Guido Soares (2003, p.624) os animais migratórios, v.g. peixes tranzonais, não necessitam passaportes para passarem do território de um Estado a outro, assim também os animais e plantas em extinção, bem como os efeitos perversos de uma poluição transfronteiriça não necessitam de vistos de permanência, ou de vistos de entrada, nos territórios de nenhum Estado.

Outro aspecto significativo que corrobora e ressalta a necessidade da cooperação entre os países consiste no desequilíbrio econômico existente entre eles. Em sua revisão anual, o Relatório sobre a Riqueza Global do Credit Suisse, publicado em 2014 na sua quinta edição, traça um retrato bastante amplo e elucidativo da distribuição da riqueza mundial. Em seus dados, denotase que a sociedade contemporânea, marcada pelo fenômeno da globalização, trouxe consigo inúmeros avanços nas mais diversas searas e que estes contribuíram para que parte dos indivíduos alcançasse uma qualidade de vida inédita. Contudo, este desenvolvimento está longe de ter se distribuído de modo equilibrado pelo globo. Enquanto a América do Norte onde habitam 6\% da população mundial deteve no ano de 2014, 35\% da riqueza global, a África 
com $12 \%$ da população mundial ficou com apenas $1,5 \%$ das riquezas globais. (Global Wealth Report, 2014, p.3)

Desde o surgimento das Organizações Internacionais, um de seus objetivos tem sido a articulação dos Estados em torno de questões, cujas respostas obtidas a nível territorial não se mostravam suficientes. Os Estados encontraram nas Organizações Internacionais (OIs) resposta à necessidade de um veículo que levasse à formação de uma consciência ambiental bem como suscitassem discussões acerca de tantos outros assuntos que devem ser enfrentados globalmente.

Com o fenômeno da globalização, as OIs ganharam projeção. Há um novo papel de interlocução entre os Estados. Elas auxiliam na formação de agendas, na indução de coalizões e servem como arenas políticas. Permitem a veiculação dos interesses diversificados, nos quais o poder não está mais calcado na força militar, mas na relação de interdependência recíproca conforme a natureza da própria necessidade em discussão. (OLSSON, 2003, p. 554)

Gilberto Rodrigues (2006, p. 211) dispõe que as políticas internacionais emanadas das Organizações Internacionais hoje compõem um guarda-chuva que abriga e muitas vezes constrange os países membros balizando e conformando suas políticas domésticas. O autor entende que abandonar o "guarda-chuva" não é visto como alternativa porque ficar "na chuva" implica em ônus político e econômico que mesmo países com alto grau de autonomia não estão propensos a arcar. ${ }^{1}$

Nesse sentido, as OIGs constituem em instituições com maiores condições de articular os múltiplos interesses dos países além de vinculá-los através de práticas cooperativas no que diz respeito às questões ambientais. A imposição de políticas ambientais que visem fomentar a cooperação somente poderá ser efetivada na medida em que se reconheça a interdependência entre os Estados.

Nesse contexto, urge o reconhecimento da necessidade de os Estados não mais enxergarem-se como fragmentos, separados uns dos outros e centrados somente nas questões ocorridas dentro de seus marcos territoriais. É preciso que, em diversos âmbitos, como por exemplo o ambiental, as bases de enfrentamento ocorram de maneira conjunta a partir do fortalecimento do

\footnotetext{
${ }^{1}$ Como exemplo, a China ingressou recentemente na OMC, cedendo a várias exigências feitas por ela, principalmente no que diz respeito a garantias trabalhistas
} 
reconhecimento da interdependência entre os Estados e do princípio da cooperação como caminho mais apropriado para equilibrar as questões globais.

\section{CONSIDERAÇÕES FINAIS}

Embora durante muitos séculos o homem tenha alimentado a ideia de que a natureza reciclaria os efeitos deletérios causados pelas atividades humanas, em especial a econômica, a expansão da produção e o crescimento econômico tornaram evidentes que esta crença não era verdadeira.

A partir da segunda metade do século XX, o modelo de crescimento econômico passou a suscitar preocupação com os danos ambientais. A Conferência de Estocolmo, realizada em 1972, pode ser apontada como o marco inicial da consciência ambiental. Tendo alçado pela primeira vez o Direito ao Meio Ambiente a direito fundamental. A partir daí inúmeras convenções e tratados foram firmados a fim de buscar-se soluções para as questões ambientais.

Em 1987, a Comissão Mundial sobre o Meio Ambiente estabeleceu o conceito de desenvolvimento sustentável como aquele que satisfaz as necessidades da presente geração sem comprometer a capacidade das gerações futuras de suprir suas próprias necessidades. A efetivação deste modelo de desenvolvimento consistiu na tônica de várias das mais importantes conferências ocorridas a partir de então. Os documentos internacionais elaborados nas Conferências Ambientais inseriram o impacto global ambiental na pauta das agendas internacionais.

A constatação de que as questões ambientais necessitavam ser seriamente enfrentadas, colocou as Organizações Internacionais como articuladoras dos Estados na busca por solucionar os problemas ambientais.

Atualmente os Objetivos do Desenvolvimento Sustentável colocaram a pobreza como o grande problema a ser enfrentado. Essa questão aliada a outras de caráter ambiental não serão satisfatoriamente respondidas caso os Estados não se unam e cooperem mutuamente na busca por soluções adequadas. Nesse sentido as OIs consistem em fundamentais instituições mediadoras de interesses e possibilitadoras da consecução de soluções eficientes e duradouras em matéria ambiental. 


\section{REFERÊNCIAS}

COPs. Disponível em: http://www.terra.com.br/noticias/ciencia/infograficos/ cops/. Visualizado em: 25/02/2016.

Global Wealth Report. Disponível em: https://publications.credit-suisse.com/ tasks/render/file/?fileID=60931FDE-A2D2-F568-B041B58C5EA591A4 . Visualizado em 30/08/2015.

Objetivos do desenvolvimento sustentável. ODS. Disponível em: http:// www.unric.org/pt/objetivos-de-desenvolvimento-sustentavel. Visualizado em 27/02/2016.

ODM. Disponível em: http://www.pnud.org.br/odm.aspx. Visualizado em: 27/ 02/2016.

PLATIAU, Ana Flávia Barros; VARELLA, Marcelo Dias; SCHLEICHER. Meio ambiente e relações internacionais: perspectivas teóricas, respostas institucionais e novas dimensões de debate. In: Revista Brasileira de Política Internacional. Vol 47 n² 2, jul/dec-2004. Brasília-DF. Disponível em: http://www.scielo.br/scielo.php?pid=S003473292004000200004\&script=sci_arttext Visualizado em: 13/08/2015.

PNUMA. Disponível em: http://www.brasilpnuma.org.br/pnuma/. Visualizado em: 26/02/2016.

RITTI, Carlos. Disponível em: http:/www.ecodebate.com.br/2015/12/18/ cop21-acordo-de-paris-avanco-nas-metas-mas-fragilidade-naimplementacao/ Visualizado em: 26/02/2016

WADA, Célia. Relatório do Clube de Roma. Disponível em: http:// www.cmqv.org/website/artigo.asp? cod=1461\&idi=1\&moe=212\&id=17072 Visualizado em 18/08/2015.

UNFCCC. Disponível em http://www.mma.gov.br/clima/convencao-dasnacoes-unidas. Visualizado em: 25/02/2016. 
BAUMAN, Zygmunt. Globalização. As consequências humanas. Rio de Janeiro: Zahar, 1999.

BECK, Ulrich. Sociedade de risco: rumo a uma outra sociedade. São Paulo: 34 .

BULGARELLI, Waldírio. Manual das sociedades anônimas. São Paulo: Atlas, 1987.

COELHO, Suani Teixeira; GOLDEMBERG, José. Energia - De Estocolmo à Rio+20. In: Direito Ambiental Internacional. GRANZIERA, Maria Luiza Machado; REI, Fernando. (Orgs.). São Paulo: Atlas, 2015.

DERANI, Cristiane. Direito Ambiental Econômico. São Paulo: Max Limonad, 2001.

DUARTE, Lilian Cristina Burlamaqui. A política ambiental internacional: uma introdução. Cena Internacional: Revista de análise em política internacional. Ano 6, nº 1, 2004. Brasília-DF.

LIMIRO, Danielli. Créditos de Carbono: Protocolo de Kyoto e Projetos de MDL. Curitiba: Juruá, 2008.

MARQUES, Floriano de Azevedo Marques Neto. Regulação estatal e interesses públicos. São Paulo: Malheiros, 2002.

OLSSON, Giovanni. Globalização e atores internacionais. In: OLIVEIRA, O.M; DAL RI, A.J (Orgs). Relações Internacionais. Interdependência e sociedade global. Ijuí: Unijuí, 2003.

OLIVEIRA, Liziane Paixão Silva; MONT'ALVERNE, Tarin Cristiano Frota. A evolução da noção de desenvolvimento sustentável nas conferências das Nações Unidas. In: GRANZIERA, Maria Luiza Machado; REI, Fernando. (Orgs.). Direito Ambiental Internacional. São Paulo: Atlas, 2015. 
QUAGLIA, Maria de Lourdes Albertini. A efetividade dos julgados da OMC em matéria ambiental. Uma análise à luz da teoria construtivista. Belo Horizonte: Arraes, 2012.

RAMONET, Ignacio. Globalização, ética e empresa. In: CORTINA, Adela (org). Construir Confiança. Ética da empresa na sociedade da informação e das comunicações. Org. Adela Cortina. São Paulo: Loyola, 2007.

RODRIGUES, Gilberto Marcos Antônio. A Organização das Nações Unidas e as políticas nacionais. In: BUCCI, Maria Paula Dallari (Org). Políticas públicas: reflexões sobre o conceito jurídico. São Paulo: Saraiva, 2006.

SOARES, Guido Fernando Silva. Direito internacional do meio ambiente. São Paulo: Atlas, 2001.

. Interdependência dos Estados no campo da proteção internacional ao meio ambiente. In: OLIVEIRA, O.M; DAL RI, A.J. (Org). Relações Internacionais. Interdependência e Sociedade Global. Ijuí: Unijuí, 2003.

TRINDADE, Antônio Augusto Cançado. Direitos humanos e meio ambiente. Porto Alegre: Safe, 1993.

Artigo recebido em: 01/03/2016

Aprovado para publicação em: 31/03/2016

Como citar: TORRES, Glaucia Cardoso Teixeira. MUNIZ, Tânia Lobo Muniz. A construção da consciência ambiental e a importância das Organizações Internacionais no enfrentamento das questões ambientais globais. Revista do Direito Público. Londrina, v.11, n.1, p.183-204, jan/abr.2016. DOI: 10.5433/1980-511X.2016v11n1p183. ISSN: 1980-511X. 